Published in final edited form as:

J Pain. 2010 April ; 11(4): 343-350. doi:10.1016/j.jpain.2009.08.003.

\title{
Race, care seeking and utilization for chronic back and neck pain: population perspectives
}

\author{
Timothy S Carey, MD MPH ${ }^{1}$, Janet K Freburger, PT PhD ${ }^{2}$, G Mark Holmes, $\mathrm{PhD}^{3}$, Anne \\ Jackman, $\mathrm{MSW}^{4}$, Stefanie Knauer ${ }^{5}$, Andrea Wallace, $\mathrm{PhD}^{6}$, and Jane Darter ${ }^{7}$ \\ ${ }^{1}$ Dept of Medicine and Cecil G Sheps Center for Health Services Research UNC Chapel Hill \\ ${ }^{2}$ Cecil G. Sheps Center for Health Services Research and Institute on Aging, UNC Chapel Hill \\ ${ }^{3}$ Cecil G. Sheps Center for Health Services Research, UNC Chapel Hill \\ ${ }^{4}$ Cecil G. Sheps Center for Health Services Research, UNC Chapel Hill \\ 5 Institute on Aging and Department of Sociology, UNC Chapel Hill \\ ${ }^{6}$ School of Nursing, University of New Mexico \\ ${ }^{7}$ Cecil G. Sheps Center for Health Services Research, UNC Chapel Hill
}

\begin{abstract}
We analyzed a statewide survey of individuals with chronic back and neck pain to determine whether prevalence and care use varied by patient race or ethnicity. We conducted a telephone survey of a random sample of 5,357 North Carolina households in 2006. Adults with chronic ( $>3$ months duration or $>24$ episodes of pain per year), impairing back or neck pain were identified and were asked to complete a survey about their health and care utilization. 837 respondents ( 620 white, 183 black, 34 Latino) reported chronic back or neck pain. Whites and blacks had similar rates of chronic back pain. Back pain prevalence was lower in Latinos (10.4\% [9.3-11.6] vs 6.3\% [3.8-8.8] ), likely due to their younger age; and the prevalence of chronic, disabling neck pain was lower in blacks (2.5\% [1.9-3.1] vs $1.1 \%$ [0.04-1.9]). Blacks had higher pain scores in the previous 3 months (5.2 vs $5.9 \mathrm{p}<0.05$ ), and higher Roland disability scores ( $0-23$ point scale): 14.2 vs $16.8, \mathrm{p}<0.05$. Care seeking was similar among races (83\% white, $85 \%$ black, $72 \%$ Latino). Use of opioids was also similar between races, at $49 \%$ for whites, $52 \%$ for blacks, and trended lower at $35 \%$ for Latinos. We found few racial/ethnic differences in care-seeking, treatment use, and use of narcotics for the treatment of chronic back and neck pain.
\end{abstract}

\section{Perspective}

This article presents new, population-based data on the issue of racial and ethnic disparities in neck and back pain prevalence and care. Few disparities were found; care quality issues may affect all ethnic groups similarly. Previous findings of disparities in chronic pain management may be decreasing, or may perhaps be site specific.

(C) 2009 The American Pain Society. Published by Elsevier Inc. All rights reserved.

Corresponding Author: Timothy S Carey MD MPH. CB 7590 UNC Chapel Hill NC 27599 Phone: 919-966-7100; FAX: 919-966-8918; Tim_Carey@unc.edu.

Publisher's Disclaimer: This is a PDF file of an unedited manuscript that has been accepted for publication. As a service to our customers we are providing this early version of the manuscript. The manuscript will undergo copyediting, typesetting, and review of the resulting proof before it is published in its final citable form. Please note that during the production process errors may be discovered which could affect the content, and all legal disclaimers that apply to the journal pertain.

The authors report no conflicts of interest. 


\section{Introduction}

The prevalence of chronic illness is increasing, leading to higher health care costs and increasing morbidity for the population. ${ }^{26}$ Our own work and that of others indicates that the prevalence of chronic back pain is increasing as well, rising from $3.9 \%$ in 1993 to $10.2 \%$ in $2006^{18} 12$. Many studies have identified racial and ethnic disparities in care-seeking and quality of care for various conditions $121^{15}$ When patients receive care based on factors other than clinical condition or patient preference, a disparity in care is present, calling into question the fundamental equity of the health care system. Although the role of race and ethnicity in the care of patients with chronic back and neck pain (BNP) has been examined previously, the results have been mixed, with some studies demonstrating lower levels of diagnostic testing and treatment of pain among racial and ethnic minorities. Previous research has often been conducted either with administrative databases, which lack clinical and functional status detail and may not adequately identify race, or through interviews conducted at care settings, which may miss disparities in care seeking since not all of those afflicted with back pain and neck pain seek care. ${ }^{3}$

We conducted a population-based survey of the prevalence and care seeking of patients with chronic back and neck pain in North Carolina. We chose North Carolina in order to make comparisons with a previous prevalence and care seeking study conducted in the same state in the early 1990 's 3 . The current study addresses the following questions: Does care seeking and the types of care sought for chronic back and neck pain differ by patient race and ethnicity? Do the treatments administered by care providers, once seen, vary by race and ethnicity?

\section{Methods}

Sampling

The sampling for the 2006 back and neck pain survey in North Carolina has been described in detail elsewhere.12 A stratified probability sample of North Carolina telephone numbers was obtained from GENESYS Sampling Systems, ${ }^{13}$ the vendor for this study. Numbers were chosen from six sampling strata, defined by the cross-classification of two variables: 1) region of the state (west, central, east) and 2) concentration of African-Americans in the population, to ensure adequate representation in the survey. 5,357 households with one or more adults 21 years or older were contacted and 9,924 adults were rostered. The household response rate was 66 percent, computed as the sum of households interviewed divided by the sum of eligible households plus an estimate of the proportion of households with unknown eligibility. ${ }^{2}$ The latter variable accounts for households with unknown eligibility that, if called an indeterminant number of times, would more than likely have been eligible and yields a more conservative response rate than assuming that the non-respondents were ineligible.

At each contacted household, an adult completed a household roster. We asked the respondent to provide the names of all adult household residents, and to indicate whether they had any back or neck pain in the past few years. The screening question was "As far as you know, did (adult name) have any back or neck problem in the past few years". These individuals were the back or neck pain candidates. If the household had one or more back or neck pain candidates, one of these candidates was randomly selected to be interviewed in more detail to determine whether s/he had chronic pain.

\section{Definition of chronic back pain}

We defined chronic pain as symptoms lasting longer than 3 months or greater than 24 separate episodes (or spells) of back or neck pain in the previous year. Back and neck pain had to be sufficiently impairing so as to interfere with the respondent's usual daily activities. The specific 
questions we asked were: "Has your low back [neck] pain been bad enough to limit your usual activities or change your daily routine nearly every day for the past 3 months?" or "Have you had any spells where your low back [neck] pain was bad enough to limit your usual activities or change your daily routine for more than 1 day?" Therefore, to be included in the chronic back/neck sample, respondents had to report both sufficient impairment and symptom duration. This definition was used to be consistent with our prior research on back pain prevalence. ${ }^{3}$ Individuals who reported both chronic back pain and neck pain completed the questions on back pain. A total of 837 individuals with chronic back or neck pain were identified and interviewed.

\section{Interview}

Respondents with chronic back or neck pain were queried regarding back or neck pain-related health care provider visits, treatments, and tests during the previous year. Respondents were specifically queried about whether they saw each of the following provider types: primary care physician, orthopedic or neurologic surgeon, doctor of chiropractic, physical medicine and rehabilitation physician, anesthesiologist, neurologist, rheumatologist, psychiatrist, physical therapist, acupuncturist, and "other" (e.g. "Did you see an orthopedic surgeon, for your [back/ neck] pain in the last year?"). If a provider was seen in the past year, then the respondent was asked about the number of visits (e.g., "How many times did you see him/her for your [back/ neck] pain in the last year?")

Respondents were queried in a similar manner regarding named diagnostic tests (CT, MRI, nerve conduction, etc.) and physical treatments (ultrasound, spinal manipulation, etc.) received during the previous year and the number of tests/treatments received. Respondents were also queried regarding medications for back/neck pain including both over-the-counter and prescription drugs (narcotics, muscle relaxants, and anti-depressants). Respondents who indicated taking narcotics were asked about frequency of use ("every day", "as needed", and "occasionally"). The window of recall for medications was restricted to the previous month due to limited recall regarding medications taken in the remote past. ${ }^{17}$ Pilot work by our group indicated that recall on number of provider visits in the past year, when compared with chart abstraction, was good, with a correlation between the two measures of 0.83 .

Race and ethnicity were identified through 2 questions: "How would you describe your race or ethnic group?" and "Do you consider yourself Hispanic or Latino?" Demographics included family income, insurance status, and employment history. Functional status was assessed using the SF-12, the Roland-Morris Disability Questionnaire (RMDQ) and Neck Disability index (NDI). ${ }^{9} 19$ Respondents were asked if they had each of the following 8 comorbidities: asthma, bronchitis/emphysema, arthritis, high blood pressure, paralysis from stroke, cancer other than skin cancer, and diabetes. Pain was assessed using a 0-10 scale, assessing pain on the day of the interview as well as recalled average pain over the previous 3 months.

The study was approved by the University of North Carolina Office Of Human Research Ethics. Written consent was waived by the IRB; all study subjects were verbally consented at the time of the interview, no personal identifiers were retained in the analytic files.

\section{Data Analysis}

All analyses were conducted using SAS or Stata (ver 9.2).

Descriptive Analyses-We conducted descriptive analyses of the prevalence of chronic low back and neck pain, and of the demographic, clinical, and health care utilization variables by race/ethnicity. Sample weights were calculated to represent the North Carolina population with chronic back or neck pain. We aggregated individuals into three distinct groups: white 
non-Latinos (hereafter "white"), African-American non-Latinos ("black"), and Hispanics or Latinos of any race ("Latino"). A small number of respondents described themselves as "half black' and we grouped them in the African-American category. Most Latinos identified their race as white $(41 \%)$ or 'other' $(50 \%)$. Four percent of the sample $(n=36)$ were not classified into any of the three groups above. These individuals were non-Latinos who indicated some other race (i.e., not white or black) or who were multiracial; because they were a disparate group and had a small sample size, they were omitted from these analyses. Between groups comparisons were made using standard parametric and non-parametric statistical tests.

Responses from individuals with continuous symptoms and very frequent episodic symptoms (>24 episodes in the past year) were very similar, so the data were combined in analyses.

Multivariate Regression Analyses-Several multivariate regression analyses were conducted, on the entire sample and on individuals with LBP only, to examine racial/ethnic differences while controlling for inter-racial differences in demographic factors, health insurance, pain level, and/or functional status among the groups. The dependent variables in these analyses were: 1) care-seeking (dichotomous variable [yes, no] indicating use of one or more health care providers in the past year); 2) total number of health care provider visits (sum of visits to all health care providers in the past year); 3 ) use of advanced imaging (dichotomous variable [yes, no] indicating whether subject received an MRI and/or CT ); and 4) use of narcotics (dichotomous variable [yes, no] indicating use of narcotics in the past month). The regression analyses on number of visits, use of advanced imaging, and use of narcotics were limited to individuals who indicated that they saw a health care provider in the past year $(n=672)$.

Control variables in the regression models included age (continuous variable), sex (dichotomous variable), years of education (continuous variable), insurance status (insured or uninsured), degree of disability (continuous variable, RMDQ or NDI), average pain level in past 3 months (continuous variable), and number of comorbidities (continuous variable). When conducting the analyses on the entire sample (i.e., patients with back or neck pain) we converted the RMDQ and NDI scores to z-scores. This was done because these two instruments measure disability on different scales (RMDQ scores can range from 0-23 and the NDI scores can range from 0-100).

All analyses utilized the sampling weights. We first conducted regression analyses entering all variables simultaneously. To explore whether socioeconomic status was confounding our findings regarding race, we compared our findings to reduced models that did not include years of education and insurance status (proxies for socioeconomic status).

Due to the small sample size for Latinos ( $n=34)$, we first conducted regression analyses for the white and black subjects only using all control variables. Based on the findings from these analyses, we conducted some additional multivariate regression analyses examining Latino differences using a smaller number of control variables.

\section{Results}

\section{Descriptive Analyses}

Of the 5,357 households contacted, 3,276 households had one or more adults with a history of back and/or neck pain. Of the adults randomly selected from each household ( $n=3,276), 2,809$ were interviewed for an individual response rate of 86 percent and an overall response rate of 57 percent (computed as the product of the household response rate $(66 \%)$ and the individual response rate $(86 \%))$. Non-responders were similar in age and race, relative to responders, but non-responders were more likely to be male (chi square test, $\mathrm{p}<.001$ ). 
The prevalence of chronic disabling back pain was similar between black and white populations at $10.4 \%$ and $9.8 \%$ (Table 1). Prevalence was lower among Latinos (6.3\%), but the Latino population in North Carolina is much younger than that of other ethnic groups. The prevalence of chronic neck pain (without chronic back pain) was greater in whites. Consistent with characteristics of the general population, blacks and Latinos with chronic back and neck pain were of somewhat lower educational status, younger, and much more likely to be poor, which we operationalized as a family income less than $\$ 20,000$ per year. However, the percent currently employed, though low at 38 and $36 \%$, was similar between whites and blacks. Uninsurance rates were similar between whites and blacks, and higher in the Latino population. Blacks were more likely to receive Medicaid and disability payments either through Medicare (i.e., Medicare and <62 years) or other types of disability insurance.

Blacks with chronic back or neck pain had higher pain scores, worse functional status as assessed by higher scores on the Roland-Morris disability index, greater number of bed days in the past month, and lower mental health scores (Table 2). Blacks were also more likely to perceive extremity weakness. The Latino group was less likely to have received spine surgery in the past and there was a similar trend with Blacks. Latinos also reported somewhat higher pain intensity, but fewer problems with physical function relative to whites.

The proportions of chronic BNP patients who sought care from any health care professional were similar, as were mean total number of visits to all providers (Table 3). Some black-white differences approached significance with a trend toward less use of spine clinics

(operationalized as "practices where you may see multiple health care providers in the care of your back (neck) pain") and a lower number of physical therapy visits for blacks. The mean number of total treatments received was significantly lower in blacks and Latinos, relative to whites, but there were few differences among the specific treatments.

We found high rates of medication use in the previous month among all individuals with chronic BNP (Table 4). One of the authors (TSC) classified narcotics as either "strong" (oxycodone, methadone, dilaudid, fentanyl etc) or "weak" (codeine, tramadol, propoxyphene etc). Rates of use of both strong and weak narcotics were similar between whites and blacks, and whites and Latinos. Similar patterns of use were also present for muscle relaxants, antidepressants, and lidocaine patches. A greater proportion of Latinos used over the counter NSAIDs and a greater proportion of Blacks used prescription NSAIDs, relative to whites.

\section{Multivariate Analyses}

Our findings from the descriptive analyses were reinforced in the multivariate regression analyses. In all of these analyses race was never a statistically significant predictor of the dependent variable (i.e., care seeking, number of provider visits, use of CT or MRI, and use of narcotics). In our reduced models excluding years of education and insurance status, race was still not significantly associated care utilization, indicating that our findings were not confounded by the association of race and socioeconomic status.

Table 5 and Table 6 summarize the results of our multivariate analyses examining black/white differences in care utilization for all subjects (Table 5) and for subjects with LBP only (Table 6). Individuals who were insured, who had more years of education, and who had a greater degree of disability were more likely to see a health care provider in the previous year and to have more health care provider visits (Table 5). Age was also inversely related to the number of health care provider visits. When the sample was limited to individuals with LBP only, the findings were similar (Table 6). Degree of disability was the only variable positively associated with imaging and narcotic use (Table $5 \&$ Table 6). 
In our analyses exploring differences in care utilization by ethnicity (i.e., Latino or non-Latino) our findings were similar. Due to the small number of Latino subjects, we used only insurance, disability, and education as control variables in the regression models. Ethnicity was not associated with care utilization in any of the models. Having insurance, a greater degree of disability, and more years of education were associated with seeking a health care provider and the number of health care provider visits. Degree of disability was associated with imaging and narcotic use.

\section{Discussion}

The prevalence of chronic back pain was slightly, but not statistically significantly, lower among blacks compared with whites using detailed and specific definitions of impairing low back pain. The impact of the disorder, as assessed by pain and functioning scales, was greater for blacks compared with whites. The prevalence of chronic neck pain was lower among blacks. Rates of care seeking, utilization of services, and use of medications were generally similar between blacks and whites. This finding is different from our group's research in the early 1990's in North Carolina. In those analyses, we also found that blacks reported higher pain scales and functional disability, but found somewhat lower prevalence and lower utilization of care and technology, including surgery. ${ }^{4}$

Our recent findings are different from the prior literature which described greater disparities in both the prevalence and treatment patterns of back pain. We shall initially discuss the prior literature on prevalence of pain, followed by comparing our findings with studies on pain treatment. Shekelle examined the RAND Health Insurance Experiment data from the 1970's and found that blacks were less likely to seek care for back pain compared with the whites (odds ratio $0.4[0.3-0.6]$ ), even when controlling for other demographic factors. ${ }^{22}$ The National Health and Nutrition Survey (NHANES) and the National Health Interview Survey (NHIS) found a lower prevalence of reported back pain in blacks compared with whites. In NHANES in the late 1970's, back pain prevalence among whites was $14.2 \%$, and among blacks $11.4 \%$. 10 Using a somewhat different definition of back pain, the NHIS in 2002 found prevalence of $27.4 \%$ in whites and 23.9 in blacks. 11 These analyses are hindered by variable and general definitions of back pain; the back pain questions are just one part of a much larger survey. A recent review described back pain prevalence as generally 'similar' among ethnic groups; our more detailed study reinforces this conclusion. 16 This review also reported lower neck pain prevalence in blacks compared to whites, consistent with our results.

Our findings indicating a trend toward lower use of surgery in minorities is similar to results from the National Spine Network, a consortium of referral practices, which found that whites were offered an operative procedure in $18 \%$ of cases compared with $11 \%$ and $14.5 \%$ in blacks and Latinos, respectively. ${ }^{25}$ A more recent study of a Midwestern worker's compensation population found similar disparities in surgical treatment. ${ }^{6}$ Total joint replacement, a procedure also offered for enhancement in pain and function rather than longevity, has demonstrated similar disparities. ${ }^{1}$

Our finding of higher pain scores in blacks is consistent with previous literature, although whether these differences reflect undertreatment, reporting differences, or a combination is unclear14 The higher mean pain scores are not due to lack of care seeking, since the proportion seeking care was similar between whites and blacks. A trend toward higher pain scores among blacks was also found when we examined non-care seekers. Although there is controversy regarding the appropriate role of narcotics in the treatment of chronic pain, in an equitable health care system use should be similar among ethnic groups. 8 Lower rates of opiate use among minorities have been found in pain-related visits to emergency departments, with odds ratios for both blacks and Latinos of about 0.7.24 Pletcher examined NHAMCS data over 13 
years (1993-2005), finding consistently lower prescription of opioids for blacks and Latinos when compared with whites.20 In a survey at 12 academic health center clinics, Chen reported that blacks had higher pain scores yet were less likely to receive opiate medications for pain (45.7\% vs 32.2\%).5 A 2006 systematic review found that a majority (65\%) of studies reported disparities in pain treatment.7

Our study has both strengths and limitations. Strengths are that respondents self-identified race and ethnicity, and the population is highly generalizable in a diverse state. Our definitions of back and neck pain were specific in terms of both duration and severity. These definitions, however, relied on patient self-report. Furthermore, our question regarding severity was broad (i.e., pain the interfered with usual activities or daily routine) and may have been interpreted differently by different subjects. Our functional status measure (The Roland-Morris scale) does, however, refer specifically to spine related impairment. We focused on a single state to provide comparability to our previous work, although this may raise questions regarding generalizability to other regions. The recent analysis by Martin and colleagues using MEPS data and a very general definition of 'spine problems' found a somewhat higher prevalence in the South compared with other regions of the US. ${ }^{18}$ The cross-sectional nature of our data prevents assessment of changes in status within subjects over time, or whether change might correlate with race or ethnicity, which may be important in chronic neck pain, where we did observe that blacks had a lower prevalence but higher pain scores. Assessing changes over time may be useful in assessing lost opportunities for care improvement. We examined both pain and back-specific functional impairment, but did not specifically measure bothersomeness or pain-linked impairment.

The previous literature may have been limited by the care settings examined: emergency departments may be particularly problematic places to convey pain information, and academic health centers have very high rates of use by low SES patients and uninsured patients with high cormorbidities, which may exacerbate disparities. Treatment of back and neck pain may also be an area in which previous disparities are decreasing over time. The apparent reduction in disparities of care for chronic, impairing back pain is certainly a positive finding, but the high rates of work disability and poor functional status, in spite of large amounts of health care utilization, represent a challenge to providers and society. Providers and health policymakers should continue to examine care settings where patients with chronic pain are treated for health disparities. But given the current high and rising rates of pain prevalence and disability, the greatest challenges in back and neck pain should be to improve the back-related outcomes for all groups of patients, regardless of race or ethnic group.

\section{Acknowledgments}

Financial Support: National Institute of Arthritis and Musculoskeletal and Skin Diseases (NIAMS) R01 AR051970; NCMHD Project EXPORT P60MD000244, and NINR T32NR08856

\section{References}

1. Agency for Healthcare Research and Quality. US Dept of Health and Human Services. AHRQ publication No 08-0041. 2008 Feb. 2007 National health care disparities report.

2. American Association for Public Opinion Research (APOR). Standard Definitions: Final Dispositions of Case Codes and Outcome Rates for Surveys. 4th ed.. Lenexa, Kansas: APOR; 2006.

3. Carey TS, Evans A, Hadler N, Kalsbeek WD, Fryer JG, McLaughlin C. Care seeking among individual with chronic low back pain. Spine 1995;20:312-317. [PubMed: 7732467]

4. Carey TS, Garrett JM. The relation of race to outcomes and the use of health care services for acute low back pain. Spine 2003;28:390-394. [PubMed: 12590217] 
5. Chen I, Kurz J, Pasanen M, Faselis C, Panda M, Staton LJ, O’Rouke J, Menon M, Genao I, Wood J, Mechaber AJ, Rosenberg E, Carey T, Callison D, Cykert S. Racial differences in opioid use for chronic nonmalignant pain. J Gen Intern Med 2005;20:593-598. [PubMed: 16050852]

6. Chibnall JT, Tait RC, Andresen EM, Hadler NM. Race differences in diagnosis and surgery for occupational low back injuries. Spine 2006;31:1272-1275. [PubMed: 16688043]

7. Citron A, Morrisson RS. Pain and ethnicity in the United States: a systematic review. J Palliat Med 2006;9:1454-1473. [PubMed: 17187552]

8. Deshpande A, Furlan A, Mailis-Gagnon A, Atlas S, Turk D. Opioids for chronic low back pain. Cochrane Database Syst Rev 2007 Jul 18;3:CD004959. [PubMed: 17636781]

9. Deyo RA, Battie M, Beurskens AJ, Bombardier C, Croft P, Koes B, Malmivaara A, Roland M, Von Korff M, Waddell G. Outcome measures for low back pain research A proposal for standardized use. Spine 1999;23:2003-2013. [PubMed: 9779535]

10. Deyo RA, Tsui-Wu YJ. Descriptive epidemiology of low back pain and its related medical care in the United States. Spine 12;1987:264-268.

11. Deyo RA, Mirza SK, Martin BI. Back pain prevalence and visit rates: Estimates from US national surveys, 2002. Spine 2006;31:2724-2727. [PubMed: 17077742]

12. Freburger JK, Holmes GM, Agans RP, Jackman AJ, Darter JD, Wallace AS, Castel LD, Kalsbeek WD, Carey TS. The rising prevalence of chronic low back pain. Arch Intern Med 2009;169:251258. [PubMed: 19204216]

13. GENESYS Sampling Services. GENESYS-IDplus. [Accessed January 2, 2008]. Available at: http://www.m-s-g.com/genesys/genesys_products/genidplus.htm

14. Green CR, Anderson KO, Baker TA, Campbell LC, Decker S, Fillingim RB, Kalanokalani DA, Lasch KE, Myers C, Tait RC, Todd KH, Vallerand AH. The unequal burden of pain: confronting racial and ethnic disparities in pain. Pain Med 2003;4:277-294. [PubMed: 12974827]

15. Jha AK, Fisher ES, Li Z, Orav EJ, Epstein AM. Racial trends in the use of major procedures among the elderly. N Engl J Med 2005;353:683-691. [PubMed: 16107621]

16. Lawrence RC, Felson DT, Helmick CG, Arnold LM, Choi H, Deyo RA, Gabriel S, Hirsch R, Hochberg MC, Hunder GG, Jordan JM, Kats JN, Kremers HM, Wolfe F. Estimates of the prevalence of arthritis and the other rheumatic conditions in the United States. Arthritis and Rheumatism 2008;58:26-35. [PubMed: 18163497]

17. Lewis JD, Stron BL, Kimmel SE, Farrar J, Metz DC, Brensinger C, Nessel L, Localio AR. Predictors of recall of over-the-counter and prescription non-steroidal anti-inflammatory drug exposure. Pharmacoepidemiol Drug Saf 2006;15:39-45. [PubMed: 16136614]

18. Martin BI, Deyo RA, Mirza SK, Turner JA, Comstock BA, Hollingworth W, Sullivan SD. Expenditures and health status among adults with back and neck problems. JAMA 2008;299:565564.

19. McCarthy MJ, Grevitt MP, Silcocks P, Hobbs G. The reliability of the Vernon and Mior neck disability index, and its validity compared with the short form-36 health survey questionnaire. Eur Spine $\mathrm{J}$ 2007;16:2111-2117. [PubMed: 17922152]

20. Pletcher MJ, Kertesz SG, Kohn MA, Gonzales R. Trends in opioid prescribing by race/ethnicity for patients seeking care in US emergency departments. JAMA 2008;299:70-78. [PubMed: 18167408]

21. Saha S, Freeman M, Toure J, Tippens KM, Weeks C, Ibrahim S. Racial and ethnic disparities in the VA health care system: a systematic review. J Gen Intern Med 2008;23:706-708. [PubMed: 18392662]

22. Shekelle PG, Markovich M, Louie R. An epidemiologic study of episodes of back pain care. Spine 1995;20:1668-1673. [PubMed: 7482015]

23. Skinner J, Weinstein JN, Sporer SM, Wennberg JE. Racial, ethnic and geographic disparities in rates of knee arthroplasty among Medicare patients. N Engl J Med 2003;349:1350-1359. [PubMed: 14523144]

24. Tamayo-Sarver JH, Hinze SW, Cydulka RK, Baker DW. Racial and ethnic disparities in emergency department analgesic prescription. Am J Public Health 2003;93:2067-2073. [PubMed: 14652336]

25. Taylor BA, Casas-Ganem J, Vaccaro AR, Hilibrand AS, Hanscomb S, Albert TJ. Differences in workup and treatment of conditions associated with low back pain by patient gender and ethnic background. Spine 2005;30:359-364. [PubMed: 15682020] 
26. Thorpe KE. Factors accounting for the rise in health care spending in the United States: the role of rising disease prevalence and treatment intensity. Public Health 2006;120:1002-1007. [PubMed: 17030050]

27. Weinstein JN, Lurie JD, Olson PR, Bronner KK, Fisher ES. United States' trends and regional variations in lumbar spine surgery: 1992-2003. Spine 2006;31:2707-2714. [PubMed: 17077740] 


\begin{tabular}{|c|c|c|c|c|c|c|c|c|c|c|c|c|c|c|c|}
\hline \multirow{6}{*}{ 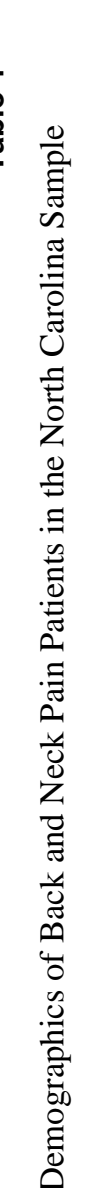 } & 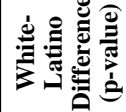 & $\begin{array}{l}\text { 总 } \\
0 \\
0\end{array}$ & $\vec{\square}$ & $\begin{array}{l}\vec{O} \\
\dot{\vec{v}}\end{array}$ & $\stackrel{ \pm}{0}$ & $\begin{array}{l}\bar{\delta} \\
\dot{Q} \\
\dot{v}\end{array}$ & $\overline{0}$ & $\begin{array}{l}\text { đ̃ } \\
0\end{array}$ & $\begin{array}{l}\overrightarrow{8} \\
\dot{\nabla}\end{array}$ & $\overline{0}$ & గి? & : & $\begin{array}{l}\overline{8} \\
\circ\end{array}$ & $\begin{array}{l}\overline{8} \\
\dot{\nabla}\end{array}$ & 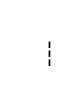 \\
\hline & 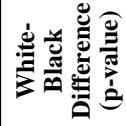 & : & $\begin{array}{l}\text { to } \\
0\end{array}$ & $\begin{array}{l}\tilde{O} \\
\text { Oे }\end{array}$ & $\begin{array}{l} \pm \\
0\end{array}$ & $\stackrel{\infty}{0}$ & $\begin{array}{l}\bar{\Xi} \\
\dot{0} \\
\dot{v}\end{array}$ & in & $\begin{array}{l}\stackrel{\partial}{0} \\
\dot{0}\end{array}$ & $\begin{array}{l}\bar{\delta} \\
\dot{\vec{v}}\end{array}$ & $\stackrel{0}{\circ}$ & $\stackrel{0}{0}$ & o̊ & $\stackrel{0}{0}$ & స̃ \\
\hline & 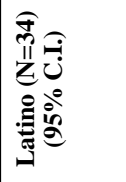 & $\begin{array}{l}\infty \\
\infty \\
\infty \\
1 \\
\infty \\
\infty \\
\tilde{c} \\
m \\
3\end{array}$ & $\begin{array}{l}\hat{\sigma} \\
\dot{j} \\
1 \\
\tilde{\delta} \\
\dot{e} \\
\dot{j} \\
\dot{j}\end{array}$ & 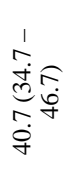 & 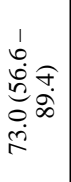 & 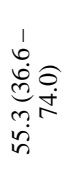 & 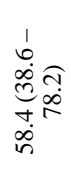 & 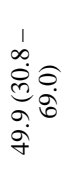 & 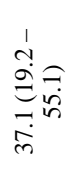 & 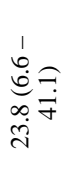 & $\begin{array}{l}\hat{n} \\
0 \\
1 \\
\text { i } \\
\text { i } \\
\text { i }\end{array}$ & 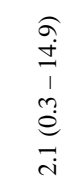 & 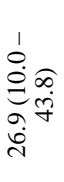 & 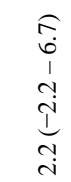 & $\stackrel{\circ}{\circ}$ \\
\hline & 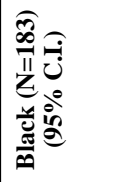 & 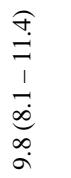 & 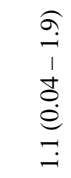 & 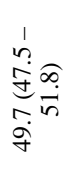 & 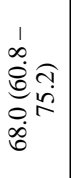 & 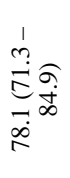 & 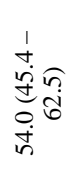 & 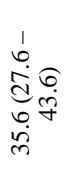 & 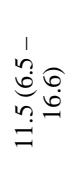 & 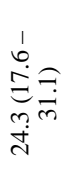 & 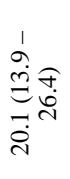 & 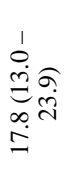 & 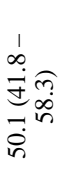 & 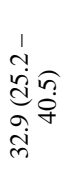 & 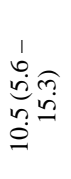 \\
\hline & 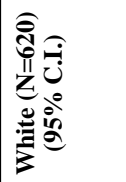 & $\begin{array}{l}1 \\
\mathfrak{a}_{0} \\
0 \\
0 \\
0 \\
0\end{array}$ & 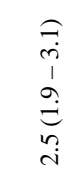 & 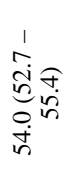 & 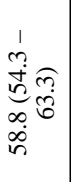 & 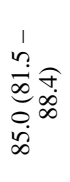 & 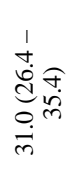 & 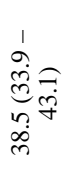 & 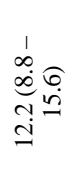 & 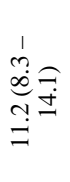 & 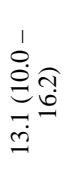 & 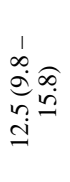 & 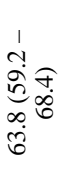 & 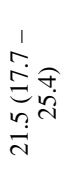 & 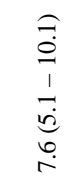 \\
\hline & 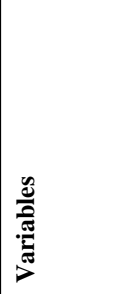 & 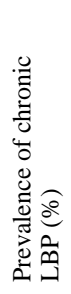 & 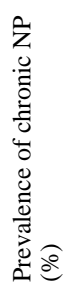 & 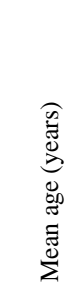 & 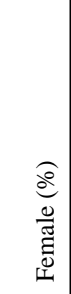 & 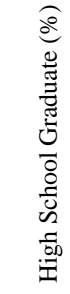 & 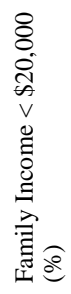 & 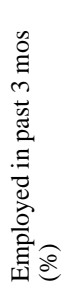 & 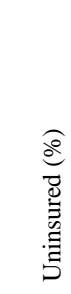 & 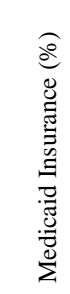 & 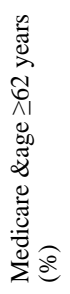 & 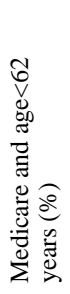 & 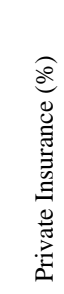 & 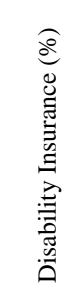 & 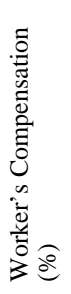 \\
\hline
\end{tabular}

J Pain. Author manuscript; available in PMC 2011 April 1. 


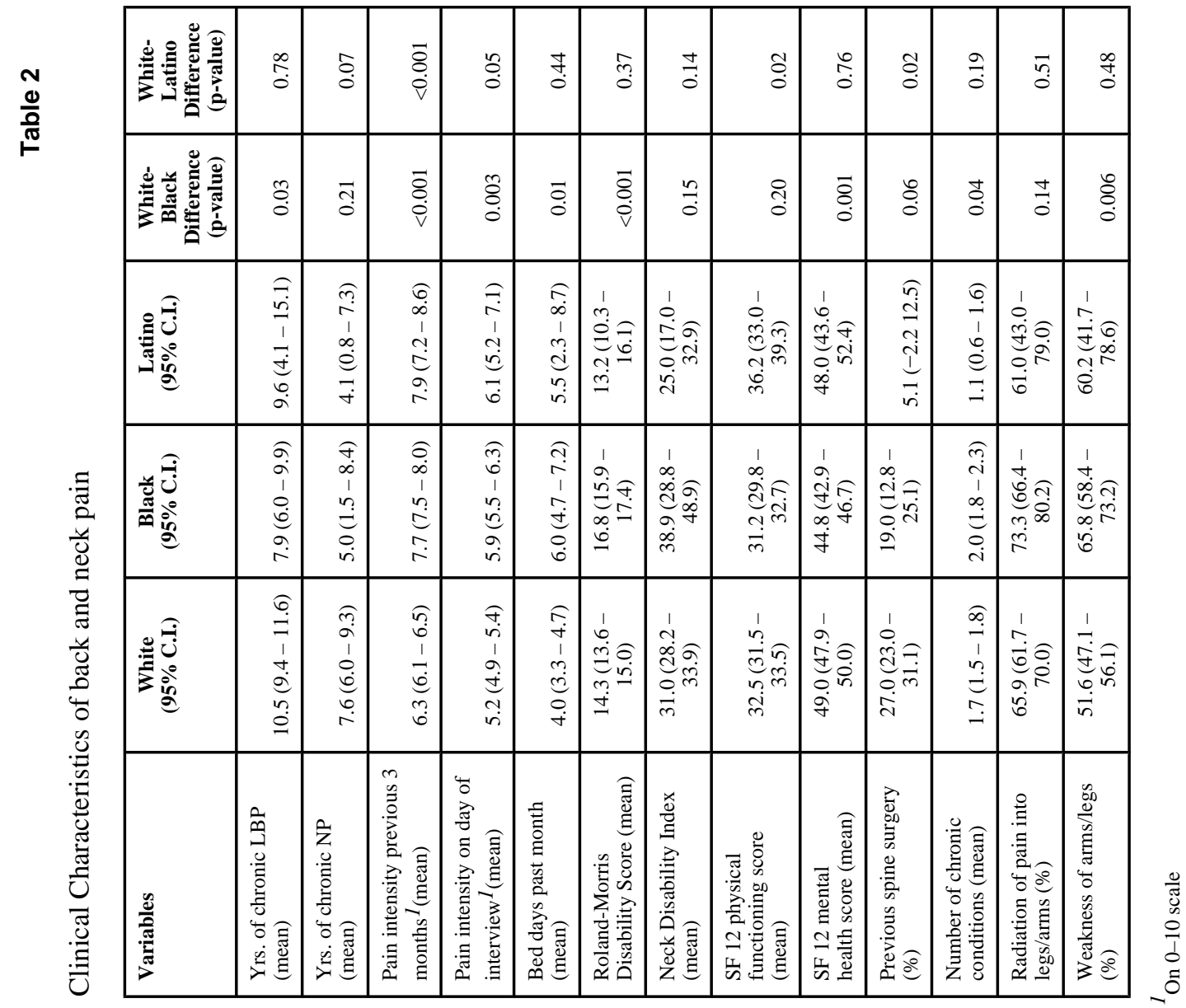

J Pain. Author manuscript; available in PMC 2011 April 1. 


\begin{tabular}{|c|c|c|c|c|c|c|c|c|c|c|c|c|c|c|c|c|c|c|}
\hline \multirow[b]{6}{*}{ 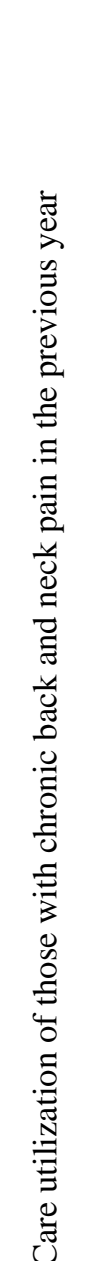 } & 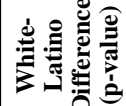 & $\bar{F}$ & $\stackrel{7}{0}$ & fั & : & ָૈ. & స్ & fo & ָָ & $\begin{array}{l}\mathfrak{n}^{2} \\
0\end{array}$ & $\stackrel{\text { oे }}{0}$ & * & ָి & $\begin{array}{c}\infty \\
\stackrel{\infty}{0} \\
\stackrel{2}{0}\end{array}$ & $\stackrel{8}{\circ}$ & $\stackrel{n}{0}$ & m. & * \\
\hline & 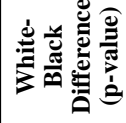 & $\stackrel{\partial}{\partial}$ & $\bar{m}$ & $\stackrel{n}{o}$ & $\stackrel{n}{0}$ & $\begin{array}{l}\tilde{O} \\
0\end{array}$ & $\stackrel{9}{0}$ & $\begin{array}{l}\infty \\
\text { ?n }\end{array}$ & $\stackrel{\circ}{\stackrel{0}{0}}$ & $\begin{array}{l}\text { d. } \\
0\end{array}$ & to & $\stackrel{R}{0}$ & ț & 芯 & $\stackrel{2}{0}$ & $\stackrel{d}{0}$ & $\stackrel{I}{0}$ & $\stackrel{\infty}{\circ}$ \\
\hline & 量 & 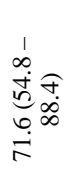 & 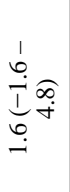 & 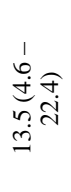 & 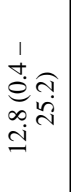 & 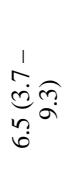 & 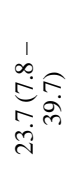 & 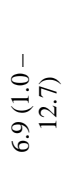 & 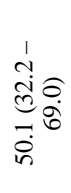 & 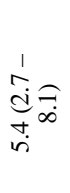 & 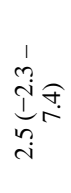 & $*$ & 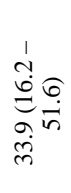 & 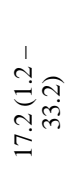 & $\begin{array}{l}\widehat{\widehat{d}} \\
\text { ते } \\
\text { อे } \\
\text { - }\end{array}$ & 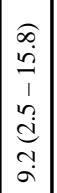 & 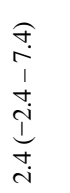 & * \\
\hline & 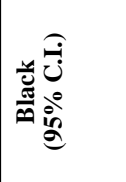 & 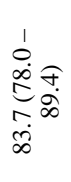 & $\begin{array}{c}n \\
\infty \\
\infty \\
1 \\
a \\
d \\
m \\
m\end{array}$ & 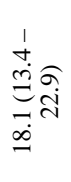 & 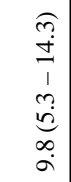 & 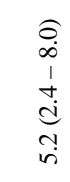 & 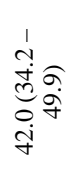 & 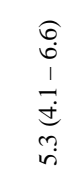 & 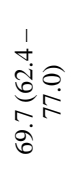 & 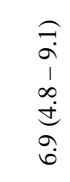 & 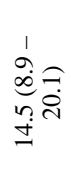 & 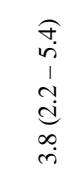 & 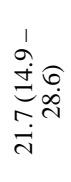 & 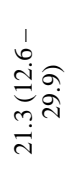 & 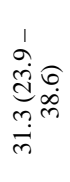 & 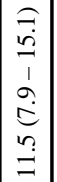 & $\begin{array}{l}f \\
f \\
b \\
1 \\
\hat{e} \\
r \\
\dot{m}\end{array}$ & 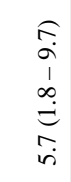 \\
\hline & 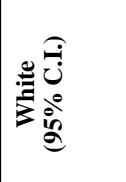 & 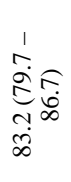 & 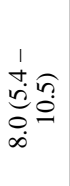 & 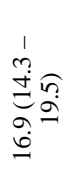 & 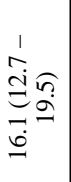 & 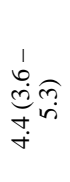 & 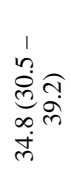 & 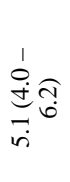 & 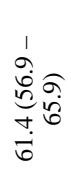 & 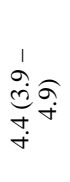 & 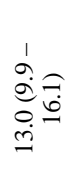 & 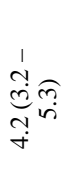 & 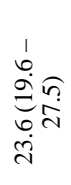 & 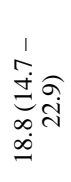 & 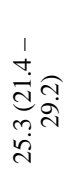 & 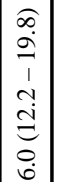 & 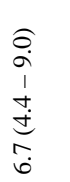 & 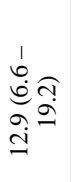 \\
\hline & 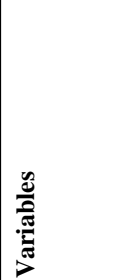 & 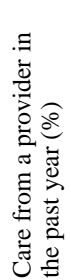 & 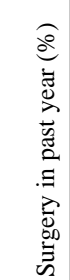 & 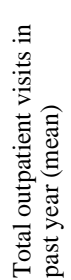 & 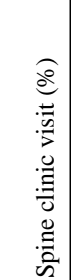 & 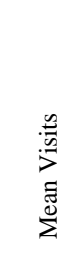 & 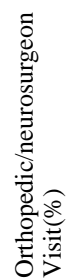 & 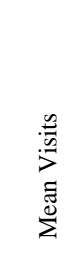 & 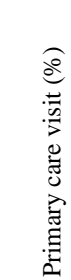 & 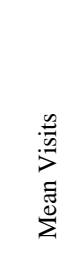 & $\begin{array}{l}\widehat{0} \\
0 \\
0 \\
0 \\
0 \\
0 \\
0 \\
0 \\
0 \\
0 \\
0 \\
0 \\
0\end{array}$ & 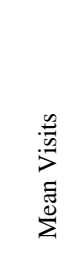 & 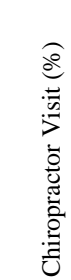 & 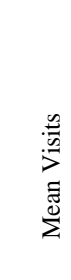 & 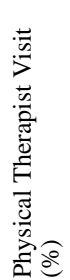 & 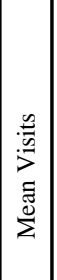 & 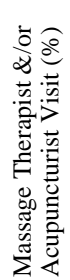 & 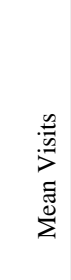 \\
\hline
\end{tabular}




\begin{tabular}{|c|c|c|c|c|c|c|c|c|c|c|c|c|c|}
\hline 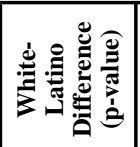 & ô & $\stackrel{f}{0}$ & ?f & त̂? & $\frac{n}{0}$ & $\stackrel{f}{\sharp}$ & o. & $*$ & $*$ & * & ते & $\frac{ \pm}{0}$ & 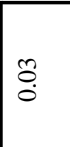 \\
\hline 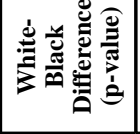 & సั & مै & $\begin{array}{c}\infty \\
\stackrel{\infty}{\circ}\end{array}$ & તે & ? & $\begin{array}{l}\infty \\
\infty \\
0 \\
0\end{array}$ & $\stackrel{8}{\circ}$ & $\begin{array}{l}\infty \\
\stackrel{0}{0}\end{array}$ & $\stackrel{8}{\circ}$ & 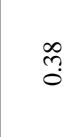 & $\stackrel{\text { Oे }}{\circ}$ & $\begin{array}{c}\hat{\infty} \\
\stackrel{\infty}{\infty}\end{array}$ & \begin{tabular}{|l} 
ț \\
0 \\
0
\end{tabular} \\
\hline نُ & 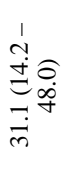 & 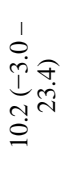 & 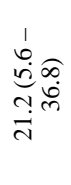 & 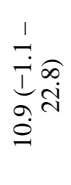 & 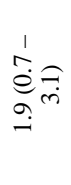 & 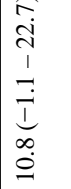 & 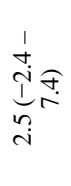 & * & $*$ & * & 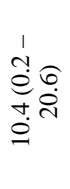 & 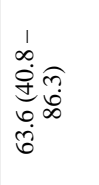 & $\begin{array}{c}1 \\
n \\
\substack{n \\
\infty \\
\infty \\
\infty} \\
= \\
=\end{array}$ \\
\hline 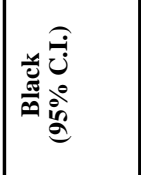 & 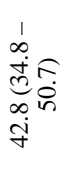 & 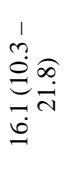 & 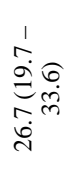 & 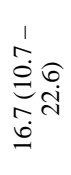 & $\begin{array}{l}\stackrel{n}{r} \\
\stackrel{1}{2} \\
\frac{1}{d} \\
m \\
m \\
m\end{array}$ & 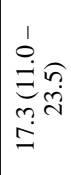 & 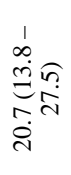 & $\begin{array}{l}\hat{\overbrace{}} \\
i n \\
1 \\
0 \\
\ddot{g} \\
-\dot{+} \\
\end{array}$ & 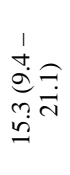 & 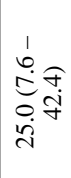 & 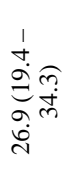 & 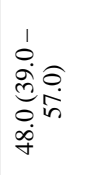 & $\begin{array}{l}0 \\
\stackrel{0}{1} \\
1 \\
1 \\
\infty \\
\omega \\
0 \\
\infty \\
\infty\end{array}$ \\
\hline 总 & 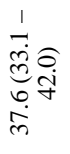 & 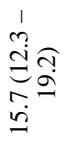 & 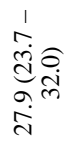 & 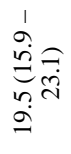 & 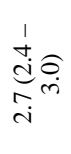 & 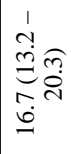 & 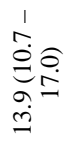 & 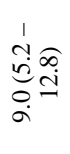 & 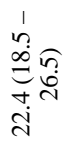 & 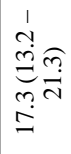 & 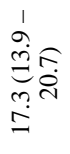 & 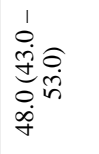 & 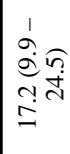 \\
\hline 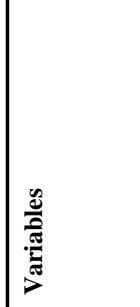 & 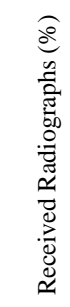 & 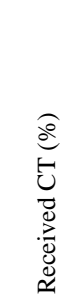 & 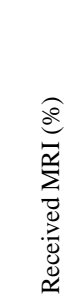 & 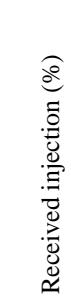 & 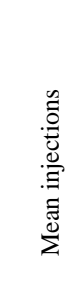 & 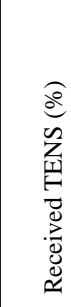 & 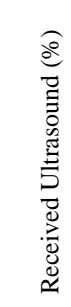 & 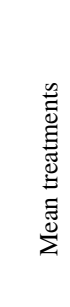 & 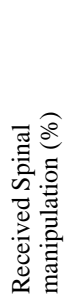 & 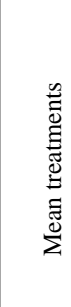 & 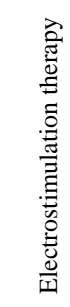 & 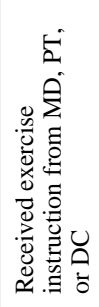 & 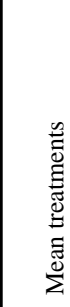 \\
\hline
\end{tabular}

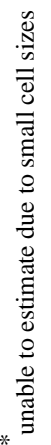




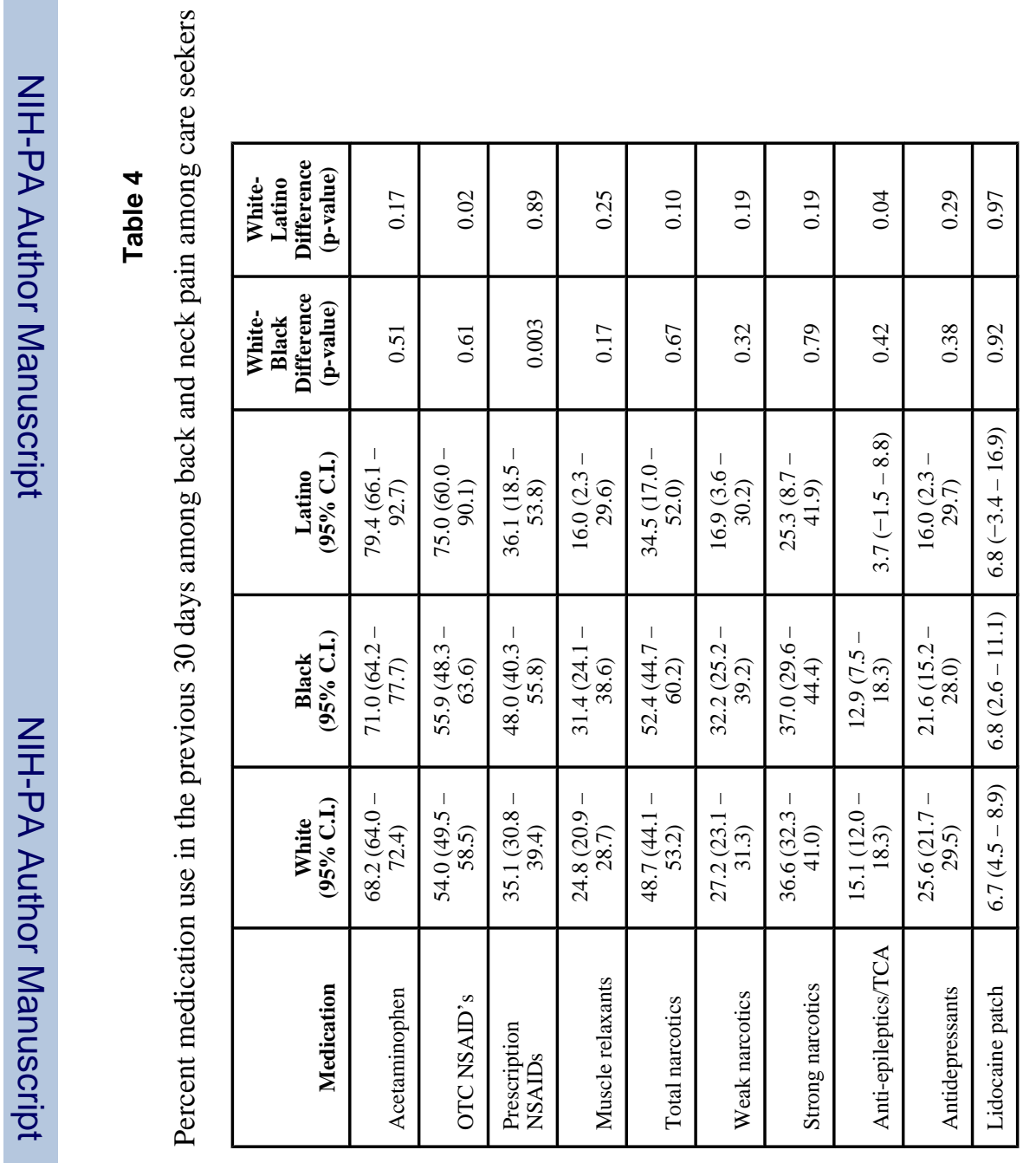

J Pain. Author manuscript; available in PMC 2011 April 1. 


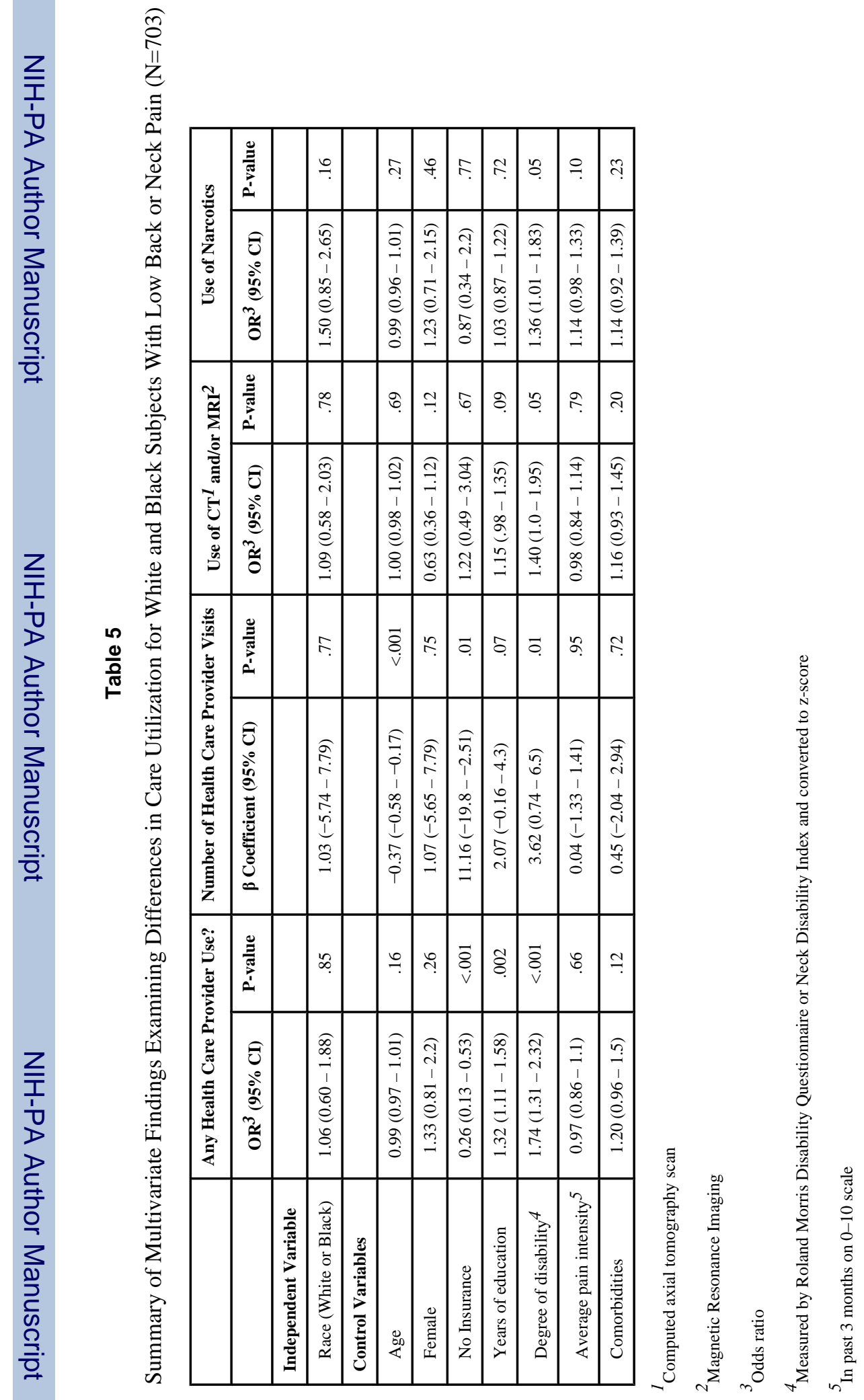




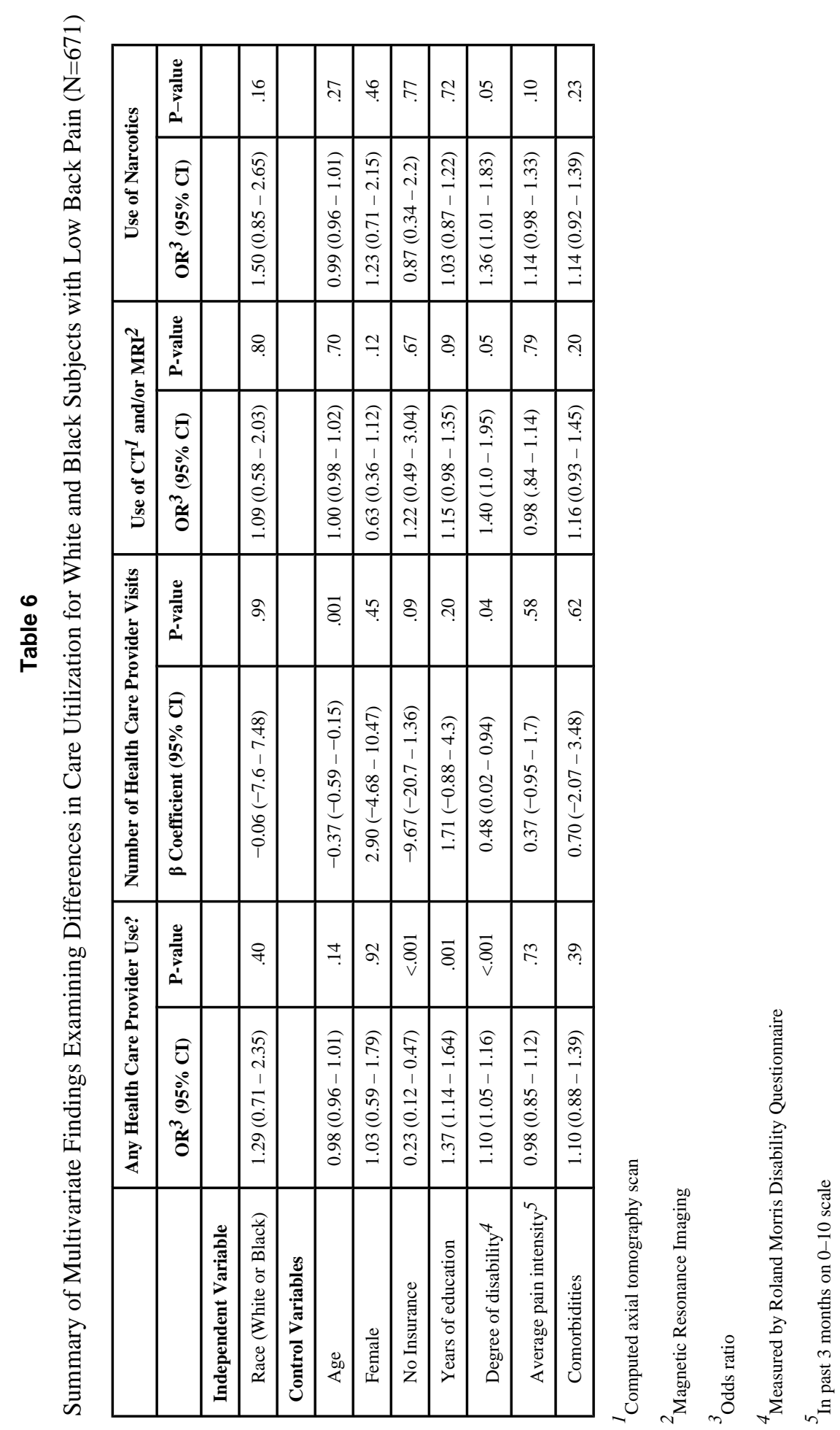

J Pain. Author manuscript; available in PMC 2011 April 1. 